\title{
Evaluating the Goals and Visions of First Year Pharmacy Students Five Years After Graduation
}

\author{
T'yanna Montague, Taliyah Townsend and Bisrat Hailemeskel* \\ Howard University College of Pharmacy, USA
}

*Corresponding author: Bisrat Hailemeskel, Clinical \& Administrative Pharmacy Sciences, College of Pharmacy, Howard

University, Washington DC, USA

\section{ARTICLE INFO}

Received: 慧 January 08, 2021

Published: 㓞 February 05, 2021

Citation: T’yanna Montague, Taliyah Townsend, Bisrat Hailemeskel. Evaluating the Goals and Visions of First Year Pharmacy Students Five Years After Graduation. Biomed J Sci \& Tech Res 33(4)2021. BJSTR. MS.ID.005442.

\begin{abstract}
Introduction: Pharmacy is a dynamic field in healthcare that allows safe medication management and usage among patients, while simultaneously providing health providers with expertise on the proper prescribing of medication. This unique field has greatly shifted its need from retail-based pharmacy to industrial and clinical pharmacy. Current research on the aspiring goals of pharmacy students is outdated and does not reflect the most current opinions of pharmacy students, in this ever-changing field, which is why this research is essential. Additionally, this research fills in the gaps that exist in current literature, which has failed to isolate the viewpoints of first-year pharmacy students only. Assessing first-year students only, compared to those of all pharmacy students allows researchers to track their beliefs from the start of school, and then reassess these beliefs at the conclusion of the students' four-year academic career. The purpose of this research is to collect data from first-year pharmacy students on what their plans are five years' post-graduation, as well as their areas of interest in pharmacy.
\end{abstract}

Methods: A total of forty-three first-year professional year students were asked to rate a series of statements on a Likert scale, to assess their viewpoints on future occupations. An online survey was developed with 15 questions and distributed to the potential participants. Out of these questions, 8 of them were demographic related questions. The data collected was analysed a statistical software.

Results: In all, results found the majority of students surveyed, have a clear vision on what they would like to be doing five-years post-graduation. $60 \%$ of students state they will not be working in retail or community pharmacy settings, with the majority $(69 \%)$ stating they will be working in a pharmaceutical industry related career. Many participants (59\%) also reported having at least a bachelor's degree prior to admission and were making under $\$ 50,000$ annually before deciding to join the pharmacy program. A third of students reported they do not have goals of owning their own business, and $36 \%$ stated they do not have set goals five-years post-graduation. Majority of students $(62 \%)$ also had a history of pharmacy related employment, prior to admission to school.

Conclusion: These results are consistent with the fact that the demand for retail pharmacists is declining, while industrial pharmacy among others, is increasing.

\section{Introduction}

A vision is defined as a clear image of how you see your future, whereas goals are specific targets that move you closer to achieving your vision [1]. Setting goals is linked to higher selfconfidence, motivation, and autonomy [1]. A 2015 study conducted by a psychologist found that those who physically wrote down their goals, were 33\% more likely to achieve their goals, than those who only formulated goals in their head. Defining one's goals and visions is vital in establishing the correct steps to take in order to achieve the desired outcome. Gauging where students' desires and goals lie early on can help researchers to better understand how mindsets can influence future outcomes. Moreover, gaining insight on what measures some students are taking can also influence where they will be five years post-graduation, in the healthcare field. A study in 2009 asked 188 pharmacy students ranging from 
first years to fourth years, about their career plans immediately after graduation. $50.9 \%$ of participants listed community retail as their desired employment, while 18\% and 8\% stated clinical and hospital pharmacy, respectively [2]. This same group was also asked where they saw themselves in 5 years, with 31\%, 24\%, and $6 \%$ stating community retail, clinical and hospital pharmacy as their desired occupations, respectively [2]. In all, the majority of the class chose community retail as both their immediate and longterm career vision.

The benefits of the first-year pharmacy students' goals and visions have been documented but there are few studies related to observing the goals students have, and the measures they are taking to get to where they want to be career wise. The current literature is outdated and was conducted at a time when retail pharmacy was in high demand. Additional research must be done, due to the shifting roles of pharmacists today. Furthermore, current research evaluates the long-term goals of pharmacy school students of all stages in their academic years, not specifically first years, as this research does. This study will explore the most current visions and goals of first year pharmacy students, five years after graduation. The goal of the study is to determine how confident and knowledgeable students are in their career plans, as well as identify their interests five years post-graduation.

\section{Methods}

A survey was distributed to 43 first professional first-year students. This survey consisted of 8 demographics related question and other six questions related to their goals and future vision post-graduation from pharmacy program. The first three non-demographic questions focused on the interest of pharmacy students five years after graduation. The last three questions focused on goals and visions five years after graduation. These survey questions were constructed by the research team using Qualtrics and then was distributed via email to the class of 2024. This study was done as part of the Drug Informatics course for first year pharmacy students. The survey was sent to 43 students and all 43 students responded which is a $100 \%$ response rate. The data distributed was rated on a five-point scale (strongly agree to strongly disagree). Further analysis was conducted using SPSS software.

\section{Results}

A total of 44 students requested to complete a survey in this study with one hundred percent response rate. Several demographics data that includes age, gender, work experience, etc. collected and as summarized in (Table 1) and (Graph 1) below. Among the survey participants, more than three-quarter of the participants $(77.3 \%)$ were female and they were under 35 years of age, with majority (59\%) between 18-34 years of age. Over half of the participants came from states other than the DMV area (District of Columbia, Maryland, and Virginia) to join our pharmacy program. However, $27.3 \%$ of the students are residents of Maryland, and one-fifth (20.5\%) reside in Virginia. Participants were also asked if they have had a job prior to admission, annual income, and the job title they held prior to joining the pharmacy program. An overwhelming number of students (95.5\%) said they had worked before joining the program. In regard to types of occupations, the majority of them (62.8\%) had a pharmacy-related job. One-third of respondents stated they had a non-pharmacy related job; with only seven $(16.3 \%)$ participants stating they previously worked in a non-healthcare related field (Graph 2). When asked about their annual income, over ten percent $(11.3 \%)$ made over $\$ 50,000$ annually while others (16.3\%) were making less than $\$ 20,000$. The remaining participants (22.6\%) made an average of $\$ 20,000$ to $\$ 50,000$. Additionally, more than half of students worked for more than four years before joining the pharmacy program (Table 2).

Table 1: Residency States Distribution $(\mathrm{N}=44)$.

\begin{tabular}{|c|c|c|}
\hline & Response Rate (\%) & No. of Responses \\
\hline $\begin{array}{c}\text { Residence Before Coming } \\
\text { to HU }\end{array}$ & & \\
\hline Maryland & 27.27 & 12 \\
\hline Virginia & 20.45 & 9 \\
\hline Other States & 43.18 & 19 \\
\hline
\end{tabular}

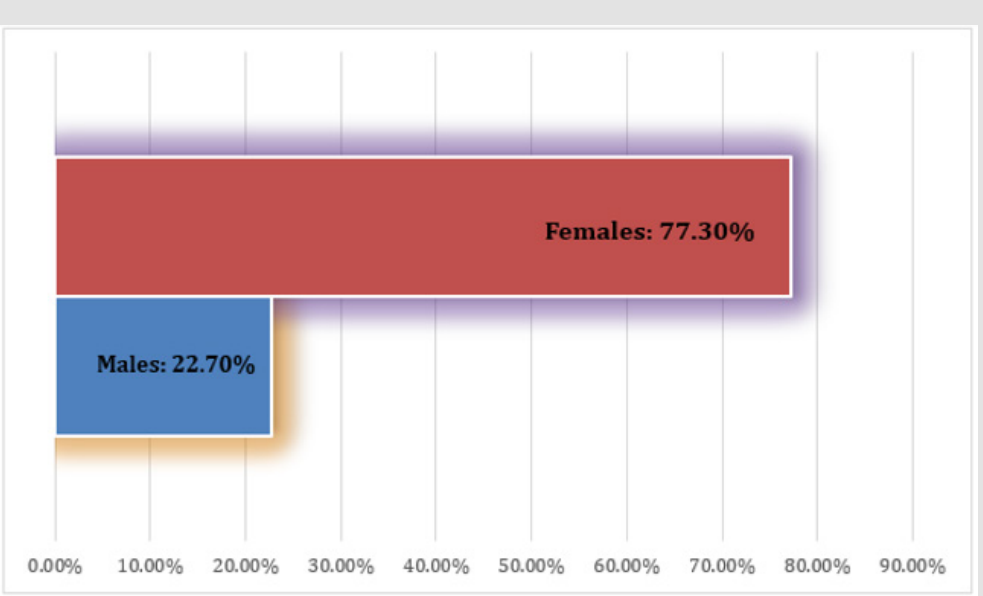

Graph 1: Gender Distribution (N=44). 


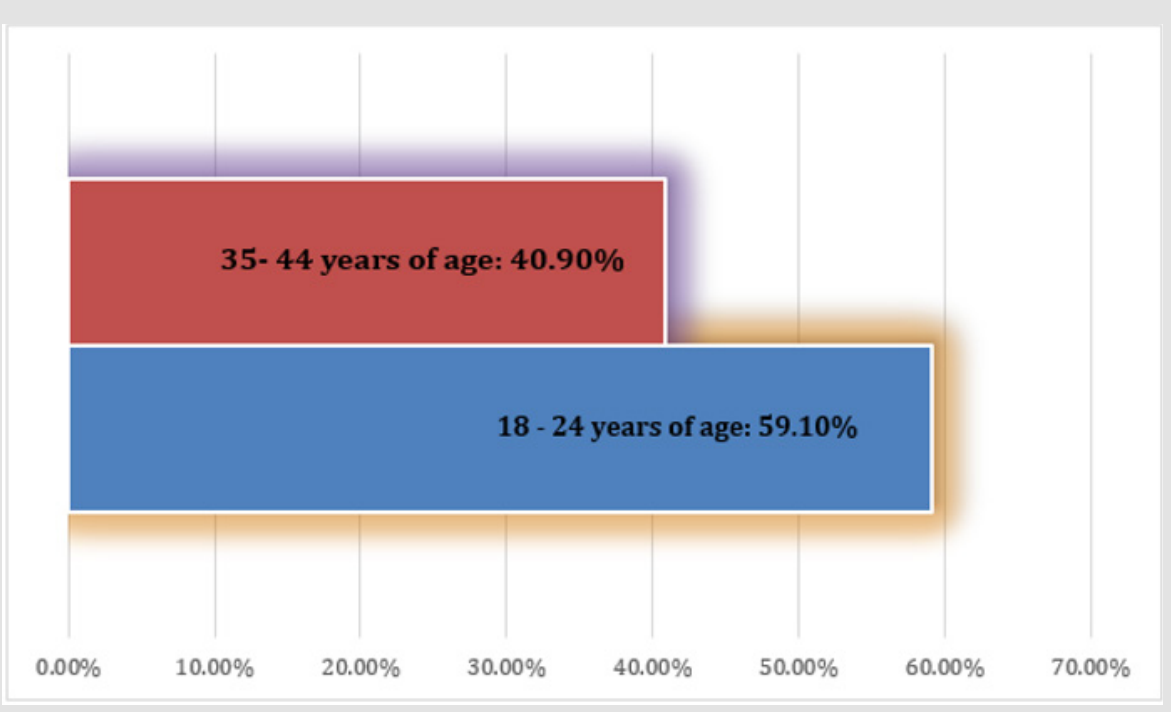

Graph 2: Age Distribution ( $\mathrm{N}=44)$.

Table 2: Responses to Prior Work-Related Questions.

\begin{tabular}{|c|c|c|}
\hline $\begin{array}{c}\text { Annual Income If You Have } \\
\text { Worked }\end{array}$ & $\begin{array}{c}\text { Response Rate } \\
\text { (\%) }\end{array}$ & No. of Responses \\
\hline$\$ 10,000-\$ 19,999$ & 16.28 & 7 \\
\hline$\$ 20,000-\$ 29,999$ & 6.98 & 3 \\
\hline$\$ 30,000-\$ 39,999$ & 18.6 & 8 \\
\hline$\$ 40,000-\$ 49,999$ & 6.98 & 3 \\
\hline$>\$ 49,999$ & 11.3 & 5 \\
\hline \multicolumn{3}{|l|}{ TYPE OF JOB HELD } \\
\hline Pharmacy Related & 62.79 & 27 \\
\hline $\begin{array}{l}\text { Non-Pharmacy but health care } \\
\text { related }\end{array}$ & 20.93 & 9 \\
\hline $\begin{array}{c}\text { No-Pharmacy or Non-Health } \\
\text { care related }\end{array}$ & 16.28 & 7 \\
\hline \multicolumn{3}{|l|}{$\begin{array}{l}\text { NUMBER OF YEARS WORKED } \\
\text { BEFORE COMING TO HU }\end{array}$} \\
\hline$<1$ & 16.28 & 7 \\
\hline $1-3$ & 32.56 & 14 \\
\hline $4-5$ & 25.58 & 11 \\
\hline$>5$ & 25.58 & 11 \\
\hline
\end{tabular}

Over one-quarter $(25.6 \%)$ of the participants reported to have been a part of the workforce for over 5 years. Respondents were asked to state their highest education they have obtained prior to joining the pharmacy program. 59.09\% of students have at least a 4-year degree, while $27.7 \%$ of students state they have some level of college, and $4.55 \%$ have an associate degree. Interestingly, close to ten percent $(9.09 \%)$ of students report having a professional degree, including a Master of Science degree. Looking at the (Table 3) below, it is apparent nearly over three-quarter of the students surveyed $(69.8 \% \%)$ have plans to work for the governmental institutions such as the FDA, USAID, CDC etc. Close to eighty percent
(79.7\%) said they are interested in working for a pharmaceutical industry. More than half of student interns (54\%) state they do not see themselves working in retail or community pharmacy settings five years post graduations. Only a small portion of students (31\%) reject the idea of owning a pharmaceutical business of their own (Graph 3). What is interesting is that one-third of the students (36.1\%) said they do not have any specific plan at the time of the survey what they are going to do 5 years after graduation from the program (Table 4).

Table 3: Prior Educational Background Reponses ( $N=44)$.

\begin{tabular}{|c|c|c|}
\hline $\begin{array}{c}\text { Highest Education Attended Before } \\
\text { Coming to HU }\end{array}$ & $\begin{array}{c}\text { Response Rate } \\
\text { (\%) }\end{array}$ & $\begin{array}{c}\text { No. of } \\
\text { Responses }\end{array}$ \\
\hline Some College & 27.7 & 12 \\
\hline 2-year degree/associate degree & 4.55 & 2 \\
\hline 4-year degree & 59.09 & 26 \\
\hline Professional degree & 9.09 & 4 \\
\hline Doctorate & 0 & 0 \\
\hline
\end{tabular}



Graph 3: Response to Job and Income Related Questions $(\mathrm{N}=44)$. 
Table 4: Survey Questions Response Related to Goals and Vision After Graduation with A Pharm D ( $\mathrm{n}=44)$.

\begin{tabular}{|c|c|c|c|c|}
\hline Survey Questions & Strongly Agree & $\begin{array}{l}\text { Somewhat } \\
\text { Agree }\end{array}$ & $\begin{array}{l}\text { Somewhat } \\
\text { Disagree }\end{array}$ & $\begin{array}{l}\text { Strongly } \\
\text { Disagree }\end{array}$ \\
\hline $\begin{array}{c}\text { My dream in five years after graduation is to work for US governmental } \\
\text { institutions such as FDA, USAID, CDC, etc. }\end{array}$ & $12(27.9 \%)$ & $18(41.9 \%)$ & $9(20.9 \%)$ & $4(9.3 \%)$ \\
\hline $\begin{array}{l}\text { I would be interested in working for the pharmaceutical industry in } 5 \\
\text { years after graduation. }\end{array}$ & $20(45.6 \%)$ & $15(34.1 \%)$ & $6(13.6 \%)$ & $3(6.8 \%)$ \\
\hline $\begin{array}{l}\text { I like to network with people and will be working in retail, five years } \\
\text { post-graduation }\end{array}$ & $6(13.6 \%)$ & $14(31.8 \%)$ & $12(27.3 \%)$ & $12(27.3 \%)$ \\
\hline I am and will be looking, to join a job that involves research & $16(36.4 \%)$ & $14(31.8 \%)$ & $10(22.7 \%)$ & $4(9.1 \%)$ \\
\hline I will establish my own business in a few years after graduation & $18(40.9 \%)$ & $12(27.3 \%)$ & $10(22.7 \%)$ & $4(9.1 \%)$ \\
\hline I may go for more school to obtain additional degrees & $10(22.7 \%)$ & $11(25 \%)$ & $13(29.6 \%)$ & $10(22.7 \%)$ \\
\hline $\begin{array}{c}\text { I do not have a specific plan of what I am going to do } 5 \text { years after } \\
\text { graduation at this time. }\end{array}$ & $4(9.1 \%)$ & $12(27.3 \%)$ & $13(29.6 \%)$ & $15(34.1 \%)$ \\
\hline
\end{tabular}

\section{Discussion}

The goal of this study was to determine the goal and vision of pharmacy students what they will be doing five years after graduation. The study was done during the participants first professional in a pharmacy school. What is interesting is that over one-third of the students (36.1\%) said they do not have any specific plan at the time of the survey what they are going to do 5 years after graduation from the program. Many say that having no goal is a goal by itself, but it is a disaster goal. However, the other two-third listed their goals where they see themselves working a few years upon graduation. The area where students show the most interest is pharmaceutical industry related jobs. About eighty percent participants $(79.7 \%)$ stated they will be looking to work in industry five years post-graduation. Close to three-fourths (70\%) of the class reported working for the CDC, FDA, or other industrial companies, would be a dream job. These findings are consistent with the fact that Evaluation Pharma states the pharmaceutical industry is projected to grow at $6.5 \%$ per year to reach $\$ 1.06$ trillion by the year 2022 [3]. The projected growth of industry pharmaceuticals could account for the strong desire for aspiring pharmacists to pursue a career in this branch of pharmacy.

Contradictory to this, is the fact that Drug Channels Institute predicts that chain, independent, and long term care outpatient dispensing pharmacies, will be decreasing by $11.2 \%$ by the year 2028 [4]. One may conclude the projected decline in retail pharmacy could be responsible for the fact that $60 \%$ of participants in the study, state they do not have plans of working in retail post-graduation. Continuing, $69 \%$ of participants believe they will own their own company five years post-graduation, whereas most students (70\%) would like to pursue research as a career path. Forty percent of the class made less than 10 thousand dollars annually, prior to admission. Most participants come from undergrad programs and aren't able to work the number of hours to make more than $\$ 10,000$ annually. These findings are consistent with the fact that students completing a bachelor's degree prior to pharmacy school in the following semester have a harder time making income. Moving along, 36\% of the class have no plan of action five years post-graduation. Students should work to develop set goals, as it is a positive quality which was proven by an earlier study. As mentioned previously, a psychologist who conducted a study found those who had written goals were 33\% more likely to achieve them, when compared to their counterparts [1].

\section{Summary}

In conclusion, it is clear the majority of first-year students have set visions and goals, in terms of future employment five years postgraduation. Many plan to either pursue industry-related affairs or plan to acquire their own business. This research was necessary to update the current literature which assesses the future goals and areas of interest of first-year pharmacy students. Being that the focus of pharmacy has shifted, and some aspects are going to be dying out in the upcoming years, it is vital to stay up to date and aware of the trends. Additionally, this data can be used in the future to evaluate the impact of goal setting on success outcomes.

\section{References}

1. Price Mitchell M (2018) Goal setting Is Linked to Higher Achievement. Psychologytoday.com.

2. Savage LM, Beall JW, Woolley TW (2009) Factors that influence the career goals of pharmacy students. Am J Pharm Educ 73(2): 28.

3. Evaluate Pharma (2019) EvaluatePharma World Preview 2018, Outlook to 2024.

4. Pharmacist Employment by Industry and Dispensing Format, 2018 vs. 2028. 


\section{ISSN: 2574-1241}

DOI: 10.26717/BJSTR.2021.33.005442

Bisrat Hailemeskel. Biomed J Sci \& Tech Res

(C) $(7)$ This work is licensed under Creative (c) Commons Attribution 4.0 License

Submission Link: https://biomedres.us/submit-manuscript.php

$\begin{array}{ll}\text { BIOMEDICAL } & \text { Assets of Publishing with us } \\ \text { RESEARCHES } & \text { Global archiving of articles } \\ & \text { - Immediate, unrestricted online access } \\ & \text { - Rigorous Peer Review Process } \\ \end{array}$

